\title{
Interactions Between Diet, Physical Activity, and the Sociocultural Environment for Older Adult Health in the Urban Subarctic
}

\author{
Britteny M. Howell ${ }^{1,2}$ (D) \\ Published online: 11 September 2019 \\ ○) Springer Science+Business Media, LLC, part of Springer Nature 2019
}

\begin{abstract}
This study sought to examine the relationship between the sociocultural factors that shape diet, physical activity, and nutritional status outcomes among seniors in Anchorage, Alaska. Alaskan seniors are an ideal study population because the state has the fastest growing senior population in the United States. Since much health research in the circumpolar north focuses on the influence of the economic or rural environment on nutrition, there is a need to investigate the ways social relationships shape diet, physical activity patterns, and nutritional status in urban spaces. This cross-sectional study included 82 community-living men and women (mean age $=74$ years) in Anchorage. Participants underwent anthropometric measurements and completed questionnaires on their dietary intake, physical activity, and the sociocultural influences on their diet and exercise practices. T-tests indicate that diet and physical activity practices in this sample do not meet national recommendations and that diet differs adversely from national reference samples. Mann-Whitney $U$ tests indicate the media and friends are associated with increases in energy expenditure. Family influences increased fruit consumption, while participation in cultural and social events increased intake of fats and sweets. Reaching older adults through a variety of channels, including the media, social networks, and culturally responsive programs can alleviate some of the barriers to healthy diet and exercise patterns.
\end{abstract}

Keywords Circumpolar north $\cdot$ Nutrition $\cdot$ Exercise $\cdot$ Social influences $\cdot$ Older adult

\section{Introduction}

Over the last decade, the proportion of people over the age of 60 has grown faster than average [1]. As people age they may face public health risks, especially in terms of nutrition and functional ability. Older adults are particularly at risk for being overweight or obese, at least until they reach extreme old age where obesity risk may decrease [2]. Although researchers understand much about the biological processes of aging, not as much is known about the sociocultural factors that contribute to cultural variation in aging [3]. Crosscultural research has shown that the experience of aging is markedly different across the world's populations because

Britteny M. Howell

bmhowell2@alaska.edu

1 Division of Population Health Sciences, University of Alaska Anchorage, BOC 233, 3211 Providence Drive, Anchorage, AK 99508, USA

2 National Resource Center for Alaska Native Elders, University of Alaska Anchorage, Anchorage, AK 99508, USA aging is a biological process rooted in sociocultural context $[4,5]$. Specifically, cultural patterns and social relationships help shape dietary and activity patterns, which play a key role in metabolic rates and the process of aging [6].

Alaskan seniors are an ideal study population because the state has the fastest growing senior population in the United States. Between 2000 and 2013, it grew by $79 \%$ and currently makes up $9.2 \%$ of the state's population. The number of Alaskans aged over 70 years has been estimated to grow by almost $60 \%$ in the next 7 years [7]. Anchorage is the largest city in the state, where approximately 401,500 people currently reside [8]. Approximately $41 \%$ of Alaska's total population lives in Anchorage [7]. It is also one of the most demographically diverse cities in the nation; the Mountain View neighborhood contains 3 of the top 10 most diverse census tracts in the country [9].

Since much health research in the circumpolar north focuses on the influence of the economic or physical environment on nutrition, there is a need to investigate the ways social relationships shape diet, physical activity patterns, and nutritional status $[10,11]$. There is a rich body of research on Alaska Native nutritional patterns in rural areas (see, 
for example [12-14]; however, a more generalized study of aging among a multi-ethnic sample in an urban location is largely lacking in the literature.

Social connections and supports are important for healthy aging, which are often affected by factors such as age, sex, and income [15]. The "sociocultural environment" refers to the social and cultural context characterized by a community's values and beliefs. These sociocultural factors influence people's perception and attitudes related to dietary and physical activity practices [16]. The reasons people choose certain foods to meet their dietary needs are multi-faceted and related to a wide range of social, cultural, and personal influences. Understanding the sociocultural environment allows researchers to uncover the pathways that may lead to healthy aging in the population of interest.

\section{Methods}

This research involves a mixed-methods approach that included participant observation, semi-structured interviews, a structured questionnaire, and anthropometric measurements of selected White, Asian, Alaska Native, and African American Alaskans aged 65 years and over. Research permissions and oversight were obtained from the University of Alaska Anchorage and the Alaska Area (tribal) IRB. Signed informed consent was obtained from all research participants after orally reviewing the approved, three-page informed consent document with participants.

All seniors recruited into the study were considered "community-dwelling" seniors, meaning that none were institutionalized or living in assisted living homes. Community-dwelling older adults were chosen for this study because they exercise more agency over their meals and activities than institutionalized adults. There were 82 seniors who participated in anthropometric measurements followed by the orally administered questionnaire.

Anthropometric measurements were taken to document nutritional status outcomes in the community and test the sample diet and nutritional status against the national reference population. The measurements included height, weight, and waist circumference (to calculate WtHR, or waist-toheight ratio) using standardized procedures [17]. The dietary assessment portion of the questionnaire consisted of the Block Food Frequency Questionnaire (FFQ), a 110-item questionnaire designed to estimate customary intake from a wide array of nutrients and food groups [18]. The accompanying Block Alaskan Foods Supplement was also selected because it contains specific local foods like berries and seafood that are readily available and a major source of nutrition for people living in the region [19]. All food items from the FFQ were categorized into the six food groups used by the CDC and USDA: vegetables, fruits, grains, proteins, dairy, and fat/sugars. Average intakes were calculated for each food item to estimate the daily servings of each food group for analysis and comparison with national recommendations.

The questionnaire also included the Community Healthy Activities Model Program for Seniors (CHAMPS) physical activity survey. The instrument covers activities undertaken for exercise purposes during the course of the day, and physically active recreational activities during a typical week in the past 4 weeks. The CHAMPS is an appropriate instrument because it was designed specifically for seniors, is considered reliable, and has been validated for use among diverse senior populations, including community-dwelling and retirement community residents [20, 21]. Physical activity frequency and energy expenditure were coded from this instrument to determine the distribution of the sample engaged in light, moderate, and vigorous physical activity for comparison with reference populations and national recommendations. These data were classified into mean weekly frequency of activities for analysis following published standards [22].

Finally, a sociocultural influences survey (SIS) was created and implemented from early participant observation, the literature, and semi-structured interviews with $15 \mathrm{key}$ informants [23]. This final section of the questionnaire contained six likert-scale questions that allowed participants to rank how important various influences are on their dietary and physical activity patterns on a scale of $1-5$, where a score of one means "this factor has no influence on my choices" ranging up to five which means "this factor is the most important influence on my choices."

\section{Data Analysis}

Dietary patterns were assessed by calculating a healthy eating index score for the sample. The Healthy Eating Index score (HEI) is a measure of diet quality developed by the USDA and used in the National Health and Nutrition Examination Survey (NHANES) that demonstrates whether the sample meets federal dietary guidelines [24]. The HEI measure was calculated for this sample based on standard published scoring where the sum of 10 dietary components are weighted equally [25]. Each component of the HEI has a possible minimum score of 0 and maximum score of 10 . The total maximum HEI score is 100 , where a higher score indicates greater dietary quality, closer to the recommended ranges and amounts of different food groups. The HEI score allows comparison of dietary quality of the sample to the national reference population of older adults.

To calculate energy expenditure, each CHAMPS activity was assigned a Metabolic Equivalent value (MET), following procedures from Stewart et al. [21] and Ainsworth et al.'s [26] physical activity compendium. For activities that were not specifically listed (e.g. water exercises), a weight value 
was assigned by interpolating a value based on other similar activities (e.g. the water exercises MET value was drawn from water aerobics in the compendium) based on published standards. These MET values were used to calculate energy expenditure for each activity, expressed in kilocalories. Energy expenditure per week in exercise-related activities was calculated using the Revised Codebook for CHAMPS Physical Activity Measures [22].

All anthropometric and questionnaire data were entered into the SPSS dataset and assessed using $t$ tests, Chi square test, ANOVA, Mann-Whitney U, and ANCOVA. Frequencies, means, and standard deviations were calculated and reported for the sample overall, as well as by sex, age, income, ethnicity, residence time in Anchorage for nutritional status, dietary intake, and physical activity practices. Frequencies and percentages were calculated for the six sociocultural influences by demographic characteristics. Frequency of response rankings were also calculated for the SIS data by sex, age, ethnicity, income, and length of time spent living in Anchorage. An alpha level of 0.05 was used to identify statistically significant results, and all tests were two-sided.

\section{Results}

The analytic sample consists of 82 older adults currently living in Anchorage, Alaska. Sixty percent of the sample was aged between 65 and 74 years old, with a mean age of $74(S D=8)$. The majority of participants were female $(63 \%)$. The sample consisted of $61 \%$ Euro-American (White), $15 \%$ American Indian/Alaska Native (AI/AN), 15\% Asian, and $10 \%$ African American (Black) participants. Fifty-four percent of the sample reported total household income below $\$ 25,000$ per year, whereas $23 \%$ earned between $\$ 25,000$ and $\$ 44,999$ and $15 \%$ earned $\$ 45,000-\$ 99,999$ annually. Less than one-tenth reported earning more than $\$ 100,000$ per year. On average, participants have been living in Anchorage for 31 years $(S D=19)$ and most lived alone $(63 \%)$.

Table 1 provides anthropometrics (height, weight, BMI, WtHR) and weight status (based on BMI categories) for the overall sample, and then separated by sex, age, ethnicity, income, the number of years spent living in Anchorage, and the number of people in the household. The table also shows statistically significant differences from $t$ tests for the three dichotomous variables: sex, age, and number of people in the household. Weight status in Table 1 is based on the following BMI categories: healthy weight (18.5-24.9), overweight (25-29.9), obese (30+), since no individuals were underweight. This Anchorage sample consisted of $82 \%$ of participants with a BMI above 25 (overweight/obese) and $90 \%$ of the sample had an unhealthy WtHR (ratio that is greater than 50\%). Only 8 individuals had healthy WtHR, and all were female.

Table 1 indicates that height and weight varied both by sex and the number of people in the household. As expected from the literature, men were taller and heavier than females. Additionally, people living with one or more persons in their home were also likely to be taller and heavier than seniors who lived alone. ANOVA indicated significant differences in age groups. Individuals aged up to 69 years old had significantly greater BMI (35) than individuals aged 70-79 years (28.09), which then went back up to 30 in the $80+$ age group. This difference is meaningful because in the middle age group, the average BMI was on the border between the overweight and obese categories, an ideal point for intervention. There is an inverted-U curve in BMI associated with length of time spent living in Anchorage among this sample. Mean BMI was 25 for individuals living in Anchorage for 10 years or less, which increased substantially to 38.8 for individuals in the 11-20 year range, then decreased to 30.8 for individuals living in Anchorage for 21 or more years and is statistically significant (also see [27]).

Although WtHR did not vary significantly by age, a statistical association appeared for length of time spent living in Anchorage, as it did for BMI. Among the $\leq 10$ year residents, the mean WtHR is 0.55 , increased to 0.65 for the 11-20 year group, where it remained for the $21+$ group (0.63). ANOVA did not indicate statistically significant findings by ethnicity or income level. Sample Anchorage residents had high rates of overweight, obesity, and unhealthy WtHR, when compared to the CDC's national reference population [28], but significant differences between the sample and the reference population only appeared in two measures. Females under age 69 in the sample were significantly shorter $(158.2 \mathrm{~cm})$ than the CDC reference population $(161.6 \mathrm{~cm})$ according to independent samples $t$ test. The second significant outcome was for waist circumference among 70-79 year old females in the sample $(92.2 \mathrm{~cm})$ compared to the reference population $(99.8 \mathrm{~cm})$. Waist circumference was compared because there are no national reference data for WtHR.

Although this sample of Anchorage seniors displays high rates of overweight, obesity, and unhealthy WtHR, this sample also has very similar anthropometric characteristics to the national reference population. The analysis revealed few significant associations with BMI or WtHR measures within the sample, with the exception of age and length of time spent living in Anchorage. Much of the literature suggests that income, sex, and ethnicity can all play a role in nutritional status [29-31]; however, this Anchorage sample may show that not all aging adults are biologically affected by such influences in the same ways.

Overall, research participants differ significantly from recommended energy and macronutrient intakes [32]. Following standard conventions for nutrition analysis with older 
Table 1 Anthropometrics and nutritional status of the sample overall, and separated by sex, age, ethnicity, income, length of residence in Anchorage (ANC), and number of people in the household (HH), and results of $t$ tests (sex, age, and number of people in the HH only)

\begin{tabular}{|c|c|c|c|c|c|c|c|c|}
\hline & \multirow[t]{3}{*}{$\mathrm{N}$} & \multicolumn{4}{|l|}{ Anthropometrics } & \multicolumn{3}{|c|}{ Weight status } \\
\hline & & Height (cm) & Weight (kg) & BMI & WtHR & Healthy & Over-weight & Obese \\
\hline & & Mean (SD) & Mean (SD) & Mean (SD) & Mean (SD) & $(\%)$ & $(\%)$ & $(\%)$ \\
\hline Overall & 82 & $162.21(10.07)$ & 81.39 (23.77) & $31.31(10.86)$ & $0.62(0.09)$ & 18.3 & 36.6 & 45.1 \\
\hline \multicolumn{9}{|l|}{ Sex } \\
\hline Male & 30 & $170.42(8.74)^{*}$ & $92.36(23.78)^{¥}$ & $33.2(12.15)$ & $0.64(0.09)$ & 6.7 & 40 & 53.3 \\
\hline Female & 52 & $157.48(7.43)$ & $75.05(23.26)$ & $30.23(9.26)$ & $0.62(0.09)$ & 25 & 34.6 & 40.4 \\
\hline \multicolumn{9}{|l|}{ Age } \\
\hline Under 69 years & 31 & $164.36(9.91)$ & $90.76(24.95)$ & $35.02(13.43)$ & $0.64(0.11)$ & 9.7 & 25.8 & 64.5 \\
\hline 70-79 years & 26 & $161.97(9.27)$ & $73.87(14.3)$ & $28.09(4.65)$ & $0.59(0.08)$ & 23.1 & 42.3 & 34.6 \\
\hline $80+$ years & 25 & $159.8(10.86)$ & 77.58 (29.83) & 30.07 (10.93) & $0.62(0.07)$ & 24 & 44 & 32 \\
\hline \multicolumn{9}{|l|}{ Ethnicity } \\
\hline Euro-American & 50 & $164.68(8.83)$ & 84.68 (22.99) & $32.23(12.36)$ & $0.61(0.09)$ & 16 & 34 & 50 \\
\hline $\mathrm{AI} / \mathrm{AN}$ & 12 & $157.83(11.84)$ & $69.18(29.24)$ & $27.12(7.36)$ & $0.58(0.12)$ & 33.3 & 50 & 16.7 \\
\hline Asian & 12 & $156.17(9.86)$ & 77.97 (24.55) & $31.43(7.52)$ & $0.66(0.09)$ & 16.7 & 33.3 & 50 \\
\hline African-American & 8 & $162.43(10.77)$ & $84.21(27.38)$ & $31.7(9.16)$ & $0.63(0.06)$ & 12.5 & 37.5 & 50 \\
\hline \multicolumn{9}{|l|}{ Income } \\
\hline$<\$ 25,000$ & 44 & $158.73(8.20)$ & $76.39(23.16)$ & $31.15(12.08)$ & $0.62(0.1)$ & 20.5 & 38.6 & 40.9 \\
\hline$\$ 25,000-44,999$ & 19 & $162.4(10.48)$ & $90.47(33.30)$ & $34.11(12.37)$ & $0.66(0.09)$ & 15.8 & 26.3 & 57.9 \\
\hline$\$ 45,000-99,999$ & 12 & $168.71(10.63)$ & $81.88(14.75)$ & $28.73(3.95)$ & $0.58(0.09)$ & 25 & 33.3 & 41.7 \\
\hline$>\$ 100,000$ & 7 & $172.49(7.39)$ & $87.3(15.15)$ & $29.21(3.86)$ & $0.6(0.06)$ & 0 & 57.1 & 42.9 \\
\hline \multicolumn{9}{|l|}{ Years in ANC } \\
\hline$<10$ years & 16 & $160.06(7.37)$ & $64.51(13.41)$ & $25.05(4.11)$ & $0.55(0.07)$ & 50 & 37.5 & 12.5 \\
\hline $11-20$ years & 17 & $161.45(11.1)$ & $93.86(36.34)$ & $38.81(5.79)$ & $0.63(0.09)$ & 5.9 & 41.2 & 52.9 \\
\hline$\geq 21$ years & 49 & $163.18(10.51)$ & 82.57 (19.7) & $30.81(5.79)$ & $0.63(0.09)$ & 12.2 & 43.7 & 53.1 \\
\hline \multicolumn{9}{|l|}{ No. of people in $\mathrm{HH}$} \\
\hline 1 & 52 & $159.94(9.06)^{\infty}$ & $77.14(20.26)^{\S}$ & $30.86(10.75)$ & $0.62(0.09)$ & 17.3 & 40.4 & 42.3 \\
\hline $2+$ & 30 & $166.15(10.67)$ & $88.74(30.07)$ & 32.09 (11.18) & $0.62(0.09)$ & 20 & 30 & 50 \\
\hline
\end{tabular}

*Significant difference in height between men and women $(\mathrm{t}(80)=7.12, \mathrm{p}=0.000)$

${ }^{\ddagger}$ Significant difference in weight between men and women $(\mathrm{t}(80)=3.22, \mathrm{p}=0.002)$

${ }^{\infty}$ Significant difference in height by number of people residing in household $(\mathrm{t}(80)=-2.8, \mathrm{p}=0.006)$

${ }^{\S}$ Significant difference in weight by number of people residing in household $(\mathrm{t}(80)=-2.08, \mathrm{p}=0.04)$

adults [33], individuals who reported less than 600 calories $(\mathrm{N}=7)$ or greater than 3500 calories per day $(\mathrm{N}=2)$ were excluded as outliers from the macronutrient calculations (see Table 2). Although men were reportedly within recommendations for protein, they over-consumed carbohydrates, fats, and sweets. Sample women significantly over-consumed protein, carbohydrates, and fats. Both men and women were below recommendations for daily fiber. Men and women met recommendations for percent of daily caloric intake from protein but consumed statistically more of their daily calories from fat than is recommended for seniors.

Once foods were classified into food groups, the most commonly consumed food items in this Anchorage sample of older adults was grains followed by fats/sugars (Table 3). T-tests indicated a significant difference only in consumption of the fat/sugar food group by sex, so that men consumed more average daily servings than women in this Anchorage sample. However, consumption of all other food categories and HEI scores did not vary statistically based on sex or number of people living in the household. Additionally, ANOVA revealed no significant differences for consumption patterns or HEI based on age, income, length of time living in Anchorage, or ethnicity.

When taken as a whole, this sample of Anchorage seniors did not meet the United States Department of Agriculture dietary recommendations for seniors [32] for any food group, but rather was low on daily consumption of vegetables, fruit, grains, protein, and dairy products. Anchorage seniors in this study also over-consumed in the fat/sugar 
Table 2 Means, standard deviations, and results of $t$ tests for macronutrients among sample participants compared to recommendations for older adults, separated by sex $(\mathrm{N}=73)$

\begin{tabular}{|c|c|c|c|c|c|}
\hline & & Sample mean & SD & $t$ value & $P$ value \\
\hline \multicolumn{6}{|c|}{ Recommended macronutrient intakes for males } \\
\hline Total calories (kcal) & 1800 & 1581.11 & 653.13 & -1.74 & 0.093 \\
\hline Protein $(g)$ & 56 & 62.15 & 29.08 & 1.10 & 0.282 \\
\hline Carbohydrates (g) & 130 & 162.93 & 68.96 & 2.48 & $0.020 *$ \\
\hline Dietary fiber $(\mathrm{g})$ & 28 & 16.3 & 9.76 & -6.22 & $0.000 *$ \\
\hline Kcal from fat $(\%)$ & $20-35$ & 43.18 & 8.99 & 7.61 & $0.000 *$ \\
\hline Kcal from protein $(\%)$ & $10-35$ & 14.27 & 2.26 & -1.67 & 0.107 \\
\hline Kcal from carbohydrates (\%) & $45-65$ & 43.99 & 8.75 & -3.57 & $0.000 *$ \\
\hline Kcal from sweets (\%) & $<10$ & 12.4 & 10.55 & 2.16 & $0.040 *$ \\
\hline \multicolumn{6}{|c|}{ Recommended macronutrient intakes for females } \\
\hline Total calories (kcal) & 1600 & 1775.91 & 741.59 & 1.609 & 0.115 \\
\hline Protein $(\mathrm{g})$ & 46 & 65.98 & 29.27 & 4.63 & $0.000 *$ \\
\hline Carbohydrates (g) & 130 & 206.09 & 77.39 & 6.67 & $0.000 *$ \\
\hline Dietary fiber $(\mathrm{g})$ & 22 & 18.9 & 9.52 & -2.19 & $0.030 *$ \\
\hline Kcal from fat $(\%)$ & $20-35$ & 39.03 & 8.37 & 7.32 & $0.000 *$ \\
\hline Kcal from protein $(\%)$ & $10-35$ & 16.05 & 6.1 & 0.061 & 0.951 \\
\hline Kcal from carbohydrates (\%) & $45-65$ & 46.38 & 11.55 & 0.22 & 0.826 \\
\hline Kcal from sweets (\%) & $<10$ & 9.96 & 7.83 & 1.70 & 0.096 \\
\hline
\end{tabular}

*Statistically significant value at the $<0.05$ level

Table 3 Mean daily servings, standard deviation (in parentheses), and results of $t$ tests for various food groups for the sample overall, and separated by age, sex, ethnicity, income, length of time in ANC, and number of people in the $\mathrm{HH}$

\begin{tabular}{|c|c|c|c|c|c|c|c|c|}
\hline & $\mathrm{N}$ & Vegetables & Fruit & Grains & Protein & Dairy & Fats/sugars & HEI \\
\hline \multicolumn{9}{|l|}{ Sex } \\
\hline Overall & 82 & $3.45(3.5)$ & $1.41(1.09)$ & $4.42(4.78)$ & $2.42(1.61)$ & $1.36(1.49)$ & $2.93(1.75)$ & $57(13.69)$ \\
\hline Male & 30 & $3.83(4.04)$ & $1.30(1.0)$ & $5.37(3.61)$ & $1.82(1.59)$ & $1.71(1.88)$ & $3.61(1.82)^{*}$ & $54.37(15.16)$ \\
\hline Female & 52 & $3.23(3.18)$ & $1.48(1.15)$ & $3.87(2.54)$ & $1.59(1,64)$ & $1.17(1.19)$ & $2.54(1.59)$ & $58.63(12.66)$ \\
\hline \multicolumn{9}{|l|}{ Age } \\
\hline Under 69 & 31 & $2.70(1.77)$ & $1.23(1.01)$ & $4.78(3.04)$ & $1.90(1.76)$ & $0.93(0.89)$ & $3.04(3.04)$ & 55.97 (14.9) \\
\hline $70-79$ & 26 & $4.02(3.23)$ & $1.70(1.21)$ & $3.51(2.78)$ & $1.47(1.45)$ & $1.22(1.13)$ & $2.78(1.47)$ & $58.46(14.07)$ \\
\hline Over 80 & 25 & $3.8(5.04)$ & $1.33(1.04)$ & $4.91(2.96)$ & $1.88(1.65)$ & $2.06(2.10)$ & $2.96(1.88)$ & $57.00(12.07)$ \\
\hline \multicolumn{9}{|l|}{ Ethnicity } \\
\hline Euro-American & 49 & $4.08(4.13)$ & $1.46(0.97)$ & $5.07(3.0)$ & $1.82(1.68)$ & $1.39(1.63)$ & $3.00(1.82)$ & $58.40(14.07)$ \\
\hline Asian & 12 & $2.83(2.39)$ & $1.63(1.27)$ & $4.35(2.79)$ & $1.43(1.56)$ & $0.93(0.93)$ & $2.79(1.43)$ & 57.75 (11.69) \\
\hline AI/AN & 12 & $2.43(1.59)$ & $1.28(1.30)$ & $2.95(2.54)$ & $1.45(1.45)$ & $1.15(0.86)$ & $2.54(1.45)$ & $56.25(13.14)$ \\
\hline African-American & 8 & $2.01(1.46)$ & $1.00(1.31)$ & $2.65(3.34)$ & $2.26(1.66)$ & $2.18(1.89)$ & $3.34(2.26)$ & $49.0(14.43)$ \\
\hline \multicolumn{9}{|l|}{ Annual income } \\
\hline$<\$ 25,000$ & 44 & $3.19(2.49)$ & $1.48(1.20)$ & $3.95(2.54)$ & $1.54(1.55)$ & $1.34(1.31)$ & $2.54(1.54)$ & $59.05(13.74)$ \\
\hline$\$ 25,000-44,999$ & 19 & $3.17(4.34)$ & $1.07(0.67)$ & $4.85(3.0)$ & $1.34(1.93)$ & $0.78(0.60)$ & $3.00(1.34)$ & $54.42(13.54)$ \\
\hline$\$ 45,000-99,999$ & 12 & $4.3(4.88)$ & $1.33(0.97)$ & $6.2(3.43)$ & $1.92(1.53)$ & $2.01(2.58)$ & $3.43(1.92)$ & $55.92(12.56)$ \\
\hline$\$ 100,000+$ & 7 & $4.44(4.20)$ & $2.04(1.36)$ & $3.10(4.41)$ & $2.83(1.53)$ & $1.97(1.45)$ & $4.41(2.83)$ & $53.86(16.55)$ \\
\hline \multicolumn{9}{|c|}{ Length of time in ANC } \\
\hline$<10$ years & 16 & $2.86(2.40)$ & $1.2(0.94)$ & $3.18(2.43)$ & $1.39(1.61)$ & $1.29(1.36)$ & $2.43(1.39)$ & $54.88(15.03)$ \\
\hline $11-20$ & 17 & $4.64(4.9)$ & $1.61(0.94)$ & $4.51(2.52)$ & $1.54(1.28)$ & $1.21(1.23)$ & $2.52(1.54)$ & $60.24(14.48)$ \\
\hline $21+$ years & 49 & $3.23(3.40)$ & $1.41(1.90)$ & $4.79(3.25)$ & $1.87(1.74)$ & $1.44(1.63)$ & $3.25(1.87)$ & $56.69(13.06)$ \\
\hline \multicolumn{9}{|l|}{ No. of people in $\mathrm{HH}$} \\
\hline 1 & 52 & $3.31(3.2)$ & $1.4(1.11)$ & $4.66(5.34)$ & $2.43(1.58)$ & $1.49(1.69)$ & $2.89(1.6)$ & $57.85(14.53)$ \\
\hline $2+$ & 30 & $3.68(4.0)$ & $1.41(1.07)$ & $4(3.65)$ & $2.42(1.71)$ & 1.14 (1.06) & $3.01(2)$ & $55.73(12.24)$ \\
\hline
\end{tabular}

*Significant difference in consumption of fats/sugars between males and females $(\mathrm{t}(80)=3.06, \mathrm{p}=0.003)$ 
group, according to $t$ tests comparing sample servings to USDA recommendations.

HEI scores for the reference population compared to sample participants, ranged from a minimum score of 23 (very poor diet) up to a maximum of 84 (high-quality diet) and averaged 57. The CDC categorizes older adults (age 65 and over) into two age groups for HEI calculations with a cutpoint at 70 years of age [25]. T-tests indicate that the CDC reference population for all older adults had HEI scores statistically higher than the sample. Since a higher score indicates healthier eating habits, the reference population has statistically better dietary quality than the sample, regardless of age.

All physical activities reported on the CHAMPS were categorized into light, moderate, or vigorous physical activities based on their corresponding MET values, and compared to CDC recommendations for older adult physical activity. These Anchorage data were then compared to national references and recommendations to determine if they differ significantly in this far northern location. The most common activities were reading, visiting with friends or family, doing light housework, walking to do errands, and using a computer. Analyses indicate that very few seniors in this Anchorage sample engage in vigorous exercise-related activities $(\mathrm{N}=6)$, so physical activities analyzed from the CHAMPS were separated as moderate intensity activities, and all activities combined.

Analyses indicated that sex is a significant factor in energy expended per week in physical activity (measured in kilocalories), such that males expended more energy in moderate activities and in all combined activities, than females (Table 4). Individuals under age 70 burned significantly more energy in vigorous activities than older individuals, despite small sample size $(\mathrm{N}=6)$. Residing in a home with at least one other individual was also significantly associated with higher energy expenditure in moderate activities and vigorous activities than individuals who live alone.

ANOVA confirms that the youngest seniors were engaging in more moderate activities than older individuals and expended significantly more energy doing so. Likewise, when all activities were combined, the younger participants engaged in more weekly activities than the older individuals. When combining all activities, there is an inverted-U curve indicating that the youngest age group ( $\leq 69$ years) expended approximately the same amount of energy per week as the oldest age group (80+); however, the middle age group (70-79 years) expended significantly more energy than the other two age groups. In other words, although the youngest age group engaged in significantly more weekly activities than the oldest age group, they did not expend significantly more weekly energy because they were engaging in a large number of low-intensity activities (such as reading).
Table 4 Mean weekly energy expenditure in calories (standard deviations in parentheses) for exercise-related activities among Anchorage residents overall, and by age, sex, income, length of time in Anchorage, ethnicity, and number in $\mathrm{HH}$, and results of $t$ tests (sex, age, number of people in $\mathrm{HH}$ only)

\begin{tabular}{|c|c|c|c|}
\hline & $\mathrm{N}$ & $\begin{array}{l}\text { Energy expendi- } \\
\text { ture of all activi- } \\
\text { ties }\end{array}$ & $\begin{array}{l}\text { Energy expenditure } \\
\text { of moderate activities }\end{array}$ \\
\hline Overall & 82 & $3955(3271)$ & $1809(2271)$ \\
\hline \multicolumn{4}{|l|}{ Sex } \\
\hline Male & 30 & $4998(3855)^{*}$ & $2713(2885)^{* *}$ \\
\hline Female & 52 & $3353(2744)$ & $1287(1643)$ \\
\hline \multicolumn{4}{|l|}{ Age } \\
\hline Under 69 & 31 & $2481(4190)$ & $2769(3091)$ \\
\hline $70-79$ & 26 & $3204(2268)$ & $1426(1480)$ \\
\hline Over 80 & 25 & $2845(1973)$ & $10,167(1084)$ \\
\hline \multicolumn{4}{|l|}{ Ethnicity } \\
\hline Euro-American & 49 & $4636.7(3458)$ & $2200(2556)$ \\
\hline Asian & 12 & $3762(2869)$ & 1613 (2006) \\
\hline $\mathrm{AI} / \mathrm{AN}$ & 12 & $2517(2637)$ & $1016(1455)$ \\
\hline African-American & 8 & $2143(2346)$ & $844(993)$ \\
\hline \multicolumn{4}{|l|}{ Annual income } \\
\hline$<\$ 25,000$ & 44 & $3225(2531)$ & $1290(1473)$ \\
\hline$\$ 25,000-44,999$ & 19 & $4038(3372)$ & 1763 (2369) \\
\hline$\$ 45,000-99,999$ & 12 & $5236(3893)$ & $2702(2363)$ \\
\hline$\$ 100,000+$ & 7 & $6124(4888)$ & $3662(4407)$ \\
\hline \multicolumn{4}{|c|}{ Length of time in Anchorage } \\
\hline$<10$ years & 16 & $2418(1818)$ & $962(877)$ \\
\hline $11-20$ years & 17 & $5030(3637)$ & $2333(2211)$ \\
\hline $21+$ years & 49 & $4084(3375)$ & 1903 (2547) \\
\hline \multicolumn{4}{|l|}{ No. of people in $\mathrm{HH}$} \\
\hline 1 & 52 & $3486(2711)$ & $1488(1668)$ \\
\hline $2+$ & 30 & $4769(3984)$ & $2365(3001)^{* * *}$ \\
\hline
\end{tabular}

*Significant difference in EE for all activities by $\operatorname{sex}(\mathrm{t}(80)=2.25$, $\mathrm{p}=0.03)$

**Significant difference in EE for moderate activities by sex $(\mathrm{t}(80)=2.86, \mathrm{p}=0.005)$

***Significant difference in EE for moderate activities by \# people in $\mathrm{HH}(\mathrm{t}(80)=-1.71, \mathrm{p}=0.008)$

The data also revealed one statistically significant association in physical activity by ethnicity. The weekly frequency of all activities performed was statistically lower for American Indian/Alaska Native participants when compared to White or Asian participants. There were no significant differences for frequency of moderate activities, moderate caloric expenditure, or all caloric expenditure by ethnicity or number of people residing in the household. Income was not a significant factor on the number of weekly moderate activities or all combined activities performed; however, there was a statistical association between energy expenditure on moderate activities and income. Although frequency of weekly activities may not be significantly different, the 
highest income groups tended to engage in activities that burn more energy than the lowest income group. Length of time living in Anchorage was not statistically related to any physical activity measures.

The CDC recommends at least $150 \mathrm{~min}$ of moderate intensity activity every week in addition to muscle-strengthening activities twice a week, or 75 min of vigorous-intensity activity in addition to muscle-strengthening activities twice a week, or a mix of moderate and vigorous-intensity activities in addition to muscle-strengthening activities twice a week for seniors [34]. Only one participant met these recommendations for physical activity ( $1.2 \%$ of the sample); however, approximately $35 \%$ of the national reference population of seniors meet recommended guidelines [35]. Therefore, this Anchorage sample was significantly below the national reference sample and did not meet recommendations for physical activity.

At least half of all participants recognized the role of family members, cultural identity, and participation in cultural events on their dietary and activity patterns. However, fewer participants indicated that the media, friends, or subsistence practices have much effect on their dietary and physical activity patterns [23]. Responses on the 5-point scale are condensed into two categories (following [36, 37]); has no to very little role in my choices (low) and has some to most important role in my choices (high) in order to test for differences by sex, age, ethnicity, income, length of time in Anchorage, and number of people in the household (Table 5). Chi square tests of difference for sex revealed no significant findings for any of the six sociocultural variables; however, differences were found for age, ethnicity, length of time living in Anchorage, and number of people in the household.

Significant differences from Chi square tests by age showed that seniors in the oldest age group (80+ years old) reported a stronger role of the media on their dietary and activity patterns than seniors below age 80 . Additionally, there was a stronger relationship between the influence of friends on younger seniors (below age 70) as opposed to seniors over age 70 for diet and activity. However, the remaining sociocultural influences did not vary significantly by age.

Ethnicity was only a significant factor in the measure of cultural identity. Participants who were Alaska Native were statistically more likely to report high influence of their cultural identity on their dietary and physical activity patterns than other ethnic groups. The media, friends, family, participation in cultural events, and subsistence knowledge and skills did not vary significantly by ethnic groups. There were also no significant differences for any of the sociocultural influences by income.

However, sample participants who had lived in Anchorage the longest $(21+$ years) reported significantly stronger influences of friends on their diet and activity practices than participants who had lived in Anchorage for less than 20 years. Additionally, seniors living with at least one other person in their homes were also statistically more likely to report a higher influence of their family members on diet and activity patterns. This result is not surprising since the other person living in the home with them is often a family member, usually spouse or children.

Mann-Whitney U nonparametric tests were used to test each of the SIS variables condensed into the two response options. Significant results from the tests revealed associations between the media influence and greater energy expenditure in all activities and in moderate activities. Likewise, the influence of friends was also related to energy expenditure in all activities. The test resulted in significant findings for the influence of family on fruit consumption, as well as the influence of participating in cultural events on the consumption of fats/sweets. Greater influences from the media and friends resulted in increased energy expenditure, greater influence from family was related to increased fruit intake, and greater participation in cultural events was associated with increased intake of fats/sweets. No associations were found for cultural identity or subsistence knowledge and skills in the nonparametric tests. Likewise, none of the SIS variables were statistically related to BMI or WtHR, HEI score, or intake of vegetables, grains, protein, or dairy.

\section{Discussion}

The literature on older adult dietary intake suggests that most seniors in the U.S. do not get enough fruit and vegetables, especially in urban settings [38]. Likewise, research suggests that high rates of overweight and obesity in urban locations [39] and in the circumpolar north are not uncommon [40]. These project findings seem to support the assertion that the pressures of urban living are compounded with the stressors of the Subarctic environment to create a local biology of high rates of cross-cultural obesity in later life [41-43]. However, improved activity and nutritional outcomes can come from programs and interventions that reduce the stressors of urban isolation, increase physical activity opportunities and intake of fruit and vegetables by bolstering social supports [44-46].

Study seniors in their 70s had higher BMIs than participants in their 60s or 80s. This relationship is supported in the research, where it is common for the oldest-old to lose weight and become more frail [47]. These findings and other research suggest that weight reduction strategies are best implemented with younger seniors while the oldest seniors may benefit more from fall prevention, balance, and strength training to reduce frailty $[48,49]$.

Healthy aging strategies should intervene in diet and activity patterns before reaching older adulthood to prevent 


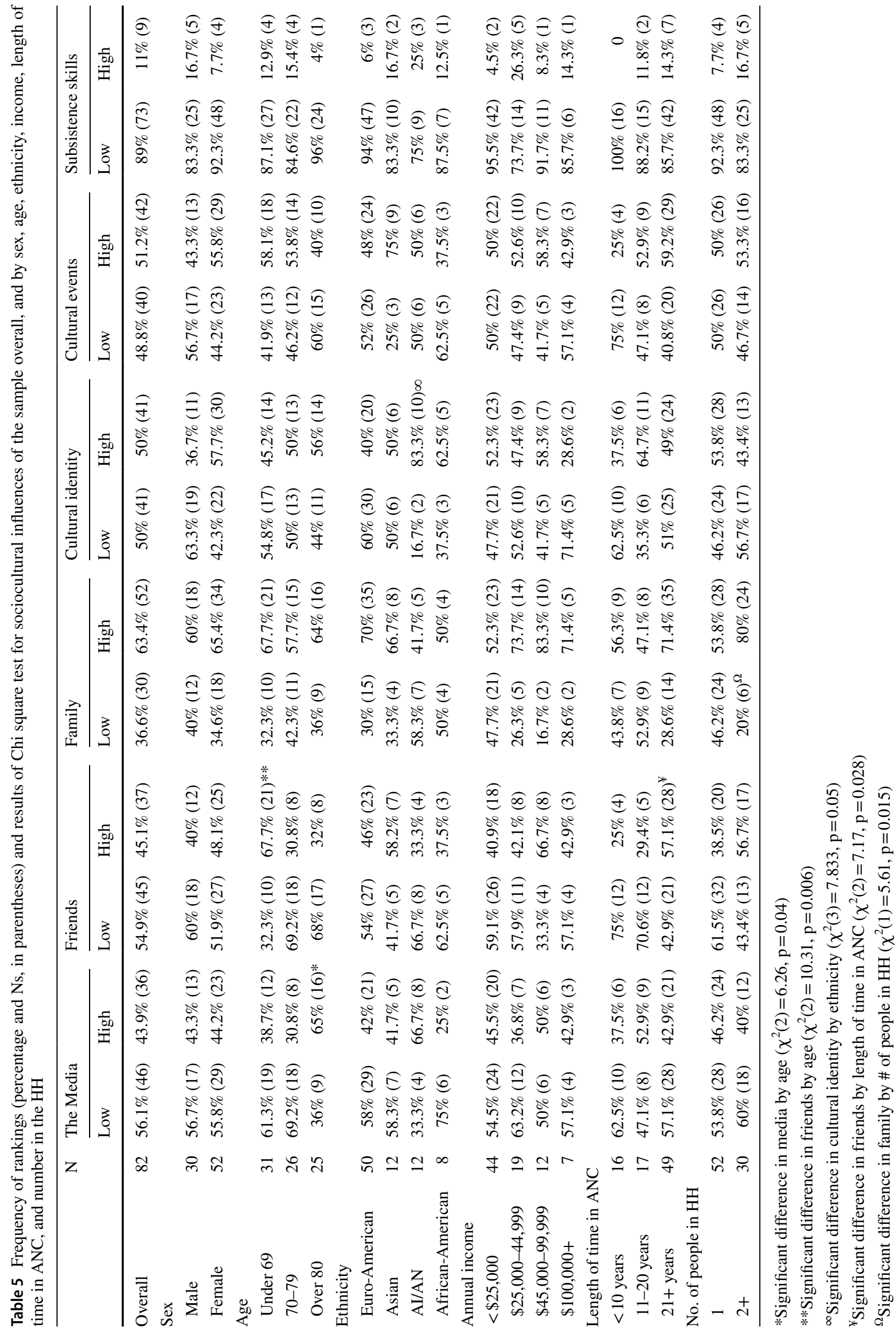


these dramatic increases in body weight and nutritional status that seem to accompany increasing age and length of time spent in Anchorage. The literature also suggests that new arrivals to urban locations often adjust to their new surroundings through dietary and activity patterns that promote weight gain [50,51]. Since new arrivals are also unlikely to have extensive social connections, interventions that provide social supports for new senior residents are well positioned to positively affect diet, activity, and nutritional status in Anchorage [10, 52]. Programs that are successful at increasing dietary quality and physical activity among American Indian/Alaska Native peoples are also culturally tailored, community-based projects that include subsistence components [53-57].

Seniors in this project reported a variety of sedentary activities but few moderate or vigorous physical activities. Television watching and reading made up much of the day for most seniors. Younger seniors were more likely to engage in moderate activities, vigorous activities, and expended more weekly energy than the oldest seniors, which is to be expected since research suggests adults tend to decrease activity as age and frailty increase [58, 59]. Although these findings link living with at least one other person to increased body weight, these analyses also show that living with a spouse/roommate can increase weekly energy expenditure. Increasing activity among seniors may be best done at the household level, since these housemates have such an influence on behaviors.

Exercise results in this project also indicate that Anchorage senior women expend less weekly energy than men, and that Alaska Native participants expended the least energy when compared to all ethnic groups. Both of these findings are evidenced in the older adult literature, where women and ethnic minorities tend to obtain the least amount of exercise in old age [60]. Although some research suggests indigenous circumpolar populations obtain high levels of physical activity [61], most research among Alaska Natives suggests the opposite [62, 63]. Physical activity programs should be targeted to Alaska Native seniors living in Anchorage, especially those that are culturally-appropriate and meaningful, such as subsistence activities $[64,65]$.

The media can influence older adult's behaviors, which may be no surprise considering retired adults spend nearly $80 \%$ of their waking time engaged in sedentary pursuits such as reading, using computers, and watching TV [66, 67]. In this project, $89 \%$ of study participants $(\mathrm{N}=73)$ reported daily reading and $85.4 \%$ of participants $(\mathrm{N}=70)$ reported daily television watching. Although Tennant et al.'s research [68] suggests that younger seniors are more savvy with electronic media, this project found that older seniors reported greater influence of the media on their choices. It could be that older seniors consume more media than younger seniors in Anchorage, since younger seniors are more likely to be spending their day time working or volunteering and older seniors are more likely to be retired and spending their day time consuming various sources of media [69]. Public health interventions should utilize various media outlets to reach seniors in Anchorage of all ages, especially the hard-to-reach oldest adults where research suggests targeted media can increase physical activity [70].

A statistically significant association was found for the influence of friends on younger seniors. Research shows that younger seniors are more likely to have varied social connections than the oldest seniors, which explains this connection between younger age and influence of friends [71]. This is because older seniors are more likely to have experienced the loss of many of their friends through declining health, moving away, or death, leading to greater rates of isolation [44]. Seniors who had lived in Anchorage longer also reported a greater influence of their friends on diet and activity behaviors than newly arrived residents. Older adults who have newly arrived in Anchorage are less likely to have established friendships than seniors who have lived in Anchorage for several years. Therefore, interventions that increase social opportunities for seniors can increase their healthy aging behaviors and general well-being.

Living with spouses, children, or other relatives was a common arrangement among those seniors who reported that family was an important influence. As expected, family members living in the same home were likely to influence the diet and activity choices of study participants. Although the literature has found that family can influence both healthy and unhealthy behaviors [72, 73], public health initiatives that include entire households in promoting healthy behaviors can have the greatest impact on healthy aging [74-76].

Using a framework of the social determinants of health underscores the importance of social and cultural influences on diet, activity, and nutritional status among urban Anchorage's senior population. Sociocultural factors have a greater effect on seniors' diet and exercise patterns than they do on BMI and WtHR. Features of the sociocultural environment might influence some diet and exercise habits but are not entirely responsible for the high rates of obesity within the community indicating a need for more culturally-responsive programs that maintain relationships with family members and make connections between seniors with similar healthy aging goals in order to improve diet and activity practices in the urban Subarctic.

Acknowledgements Financial support for this research was provided by the National Science Foundation Arctic Social Science Program (\#PLR-1331019), Central States Anthropological Society's Leslie A. White Award, Alaska Anthropological Association's James VanStone Award, and Hope Community Resources. The content of this work is solely the responsibility of the author, who wishes to express gratitude 
to Deborah Crooks and Ryan Harrod for providing critical feedback on this manuscript.

\section{Compliance with Ethical Standards}

Research involving Human Participants This study obtained informed consent from the University of Alaska Anchorage and the Alaska Area (tribal) IRB.

\section{References}

1. U.S. Department of Health Human Services. (2016). A profile of older Americans: 2015. Washington, DC: US Department of Health and Human Services, Administration on Aging.

2. Inelmen, E. M., et al. (2003). Can obesity be a risk factor in elderly people? Obesity Reviews, 4(3), 147-155.

3. Ice, G. H. (2005). Biological anthropology and aging. Journal of Cross Cultural Gerontology, 20(2), 87-90.

4. Sokolovsky, J. (Ed.). (2008). The cultural context of aging: Worldwide perspectives. Santa Barbara, CA: Praeger.

5. Wiley, A. S., \& Allen, J. S. (2013). Aging. In Medical anthropology: A biocultural approach (2nd ed., pp. 198-225). New York: Oxford University Press.

6. Poehlman, E. T. (1996). Energy intake and energy expenditure in the elderly. American Journal of Human Biology, 8(2), 199-206.

7. Alaska Department of Labor and Workforce Development. (2014). Research and analysis: 2013 population estimates. Retrieved from http://laborstats.alaska.gov/pop/popest.htm.

8. Alaska Department of Labor and Workforce Development. (2018). 2017 Population estimates by borough, census area, and economic region. Retrieved from http://live.laborstats.alaska.gov/pop/.

9. U.S. Census Bureau. (2016). Anchorage municipality, Alaska: Race \& Hispanic Origin QuickFacts. Retrieved from https:// www.census.gov/quickfacts/fact/map/anchoragemunicipalityalas ka,anchoragemunicipalityalaskacounty/RHI525216\#viewtop.

10. Driscoll, D. L., Dotterrer, B., \& Brown, R. A. (2013). Assessing the social and physical determinants of circumpolar population health. International Journal of Circumpolar Health. https://doi. org/10.3402/ijch.v72i0.21400.

11. Glass, T. A., Rasmussen, M. D., \& Schwartz, B. S. (2006). Neighborhoods and obesity in older adults: The Baltimore Memory Study. American Journal of Preventive Medicine, 31(6), 455-463.

12. Ballew, C., et al. (2006). The contribution of subsistence foods to the total diet of Alaska natives in 13 rural communities. Ecology of Food and Nutrition, 45(1), 1-26.

13. Bersamin, A., et al. (2006). Diet quality among Yup'ik Eskimos living in rural communities is low: The Center for Alaska Native Health Research Pilot Study. American Dietetic Association, 106, 1055-1063.

14. Nobmann, E. D., et al. (1992). The diet of Alaska native adults: 1987-1988. American Journal of Clinical Nutrition, 55(5), 1024-1032.

15. Seeman, T. E., et al. (2001). Social relationships, social support, and patterns of cognitive aging in healthy, high-functioning older adults: MacArthur studies of successful aging. Health Psychology, 20(4), 243.

16. Belon, A. P., et al. (2014). How Community environment shapes physical activity: perceptions revealed through the PhotoVoice method. Social Science and Medicine, 116, 10-21.

17. Lohman, T. G., Roche, A. F., \& Martorell, R. (1988). Anthropometric standardization reference Manual. Champaign, IL: Human Kinetics Publishers.
18. Block, G. (1998). Comparison of the Block and the Willett Food Frequency Questionnaires. American Journal of Epidemiology, 148(12), 1157-1159.

19. Alaska Food Policy Council. (2014). Alaska Food System Research. Retrieved from https://akfoodpolicycouncil.wordpress. com/alaska-food-system-research/.

20. Harada, N. D., et al. (2001). An evaluation of three self-report physical activity instruments for older adults. Medicine and Science in Sports and Exercise, 33(6), 962-970.

21. Stewart, A., et al. (2001). CHAMPS physical activity questionnaire for older adults: outcomes for interventions. Medicine and Science in Sports and Exercise, 33(7), 1126-1141.

22. UCSF Institute for Health \& Aging. (2003). Revised codebook for CHAMPS physical activity measures. Retrieved from University of California, San Francisco, Institute for Health \& Aging. http:// dne2.ucsf.edu/public/champs/resources/qxn/pdfs/revisedscoring. pdf.

23. Howell, B. M., \& Bardach, S. (2018). "It's a social thing": Sociocultural experiences with nutrition and exercise in Anchorage. Alaska. Arctic Anthropology, 55(2), 1-16.

24. Guenther, P. M., et al. (2013). Update of the Healthy Eating Index: HEI-2010. Journal of the Academy of Nutrition and Dietetics, 113(4), 569-580.

25. Center for Nutrition Policy and Promotion. (2015). Average healthy eating index scores for Americans ages 2 years and older (NHANES 2009-2010). USDA. http://www.health.gov/dietarygui delines/DGAC-HEI-2010-scores-by-age-group-NHANES-20092010.pdf.

26. Ainsworth, B. E., et al. (2000). Compendium of physical activities: An update of activity codes and MET intensities. Medicine and Science in Sports and Exercise, 32(9), S498-S516.

27. Howell, B. M. (2017). Healthy aging in the north: Sociocultural influences on diet and physical activity among older adults in Anchorage, Alaska. Theses and Dissertations-Anthropology, 24. Retrieved from https://uknowledge.uky.edu/anthro_etds/24.

28. National Center for Health Statistics. (2012). Anthropometric reference data for children and adults: United States, 2007-2010. Vital and Health Statistics, Series 11, Number 252. Data from the National Health and Nutrition Examination Survey (NHANES). Hyattsville, MD, DHHS Publication No. (PHS) 2013-1602. Retrieved from http://www.cdc.gov/nchs/data/series/sr_11/ sr11_252.pdf.

29. Donini, L., et al. (2013). Malnutrition in elderly: Social and economic determinants. The Journal of Nutrition, Health \& Aging, 17(1), 9-15.

30. Ice, G. H., et al. (2011). Caregiving, gender, and nutritional Status in Nyanza Province, Kenya: Grandmothers gain, grandfathers lose. American Journal of Human Biology, 23(4), 498-508.

31. Sharkey, J. R., \& Schoenberg, N. E. (2002). Variations in nutritional risk among black and white women who receive homedelivered meals. J Women Aging, 14(3-4), 99-119.

32. U.S. Department of Health and Human Services. (2015). Dietary guidelines for Americans: 2015-2020 (8th ed.). Washington DC: U.S. Department of Health and Human Services. Retrieved from https://health.gov/dietaryguidelines/2015/guidelines/.

33. Schatzkin, A., et al. (2001). Design and serendipity in establishing a large cohort with wide dietary intake distributions: The National Institutes of Health-American Association of Retired Persons Diet and Health Study. American Journal of Epidemiology, 154(12), $1119-1125$.

34. Centers for Disease Control and Prevention. (2014). How much physical activity do older adults need? Retrieved March 1, 2015, from http://www.cdc.gov/physicalactivity/everyone/guidelines/ olderadults.html.

35. CDC. (2014). Early release of selected estimates based on data from the National Health Interview Survey. Retrieved from http:// 
www.cdc.gov/nchs/data/nhis/earlyrelease/earlyrelease201506_07. pdf.

36. Allen, I. E., \& Seaman, C. A. (2007). Likert scales and data analyses. Quality Progress, 40(7), 64.

37. Grimbeek, P., Bryer, F., Beamish, W., \& D'Netto, M. (Eds.). (2005). Use of data collapsing strategies to identify latent variables in CHP questionnaire data (Vol. 2). Gold Coast: Griffith University.

38. Miller, P. E., et al. (2012). Dietary patterns differ between urban and rural older, long-term survivors of breast, prostate, and colorectal cancer and are associated with body mass index. Journal of the Academy of Nutrition and Dietetics, 112(6), 824.

39. Popkin, B. M. (1999). Urbanization, lifestyle changes, and the nutrition transition. World Development, 27(11), 1905-1916.

40. Galloway, T., et al. (2012). Obesity studies in the circumpolar inuit: A scoping review. International Journal of Circumpolar Health, 71, 18698. https://doi.org/10.3402/ijch.v71i0.18698.

41. Kuhnlein, H. V., et al. (2004). Arctic indigenous peoples experience the nutrition transition with changing dietary patterns and obesity. The Journal of Nutrition, 134(6), 1447-1453.

42. Lock, M. M., \& Kaufert, P. (2001). Menopause, local biologies, and cultures of aging. American Journal of Human Biology, 13(4), 494-504.

43. Schell, L. M., \& Ulijaszek, S. J. (1999). Urbanism, urbanization, health, and human biology: An introduction. In L. M. Schell \& S. J. Ulijaszek (Eds.), Urbanism, health, and human biology in industrialised countries (pp. 3-20). Cambridge: Cambridge University Press.

44. Brittain, K., et al. (2017). An investigation into the patterns of loneliness and loss in the oldest old. Ageing \& Society, 37(1), $39-62$.

45. Holmes, B. A., Roberts, C. L., \& Nelson, M. (2008). How access, isolation, and other factors may influence food consumption and nutrient intake in materially deprived older men in the UK. Nutrition Bulletin, 33(3), 212-220.

46. Rugel, E. J., \& Carpiano, R. M. (2015). Gender differences in the roles for social support in ensuring adequate fruit and vegetable consumption among older adult Canadians. Appetite, 92, 102-109.

47. Reinders, I., Visser, M., \& Schaap, L. (2017). Body weight and body composition in old age and their relationship with frailty. Current Opinion in Clinical Nutrition \& Metabolic Care, 20(1), $11-15$.

48. Buchner, D. M. (1997). The effect of strength and endurance training on gait, balance, fall risk, and health services use in community-living older adults. Journal of Gerontology, 52A(6), M218-M224.

49. Freire Junior, R. C., et al. (2017). The effects of a simultaneous cognitive or motor task on the kinematics of walking in older fallers and non-fallers. Human Movement Science, 51, 146-152.

50. Himmelgreen, D. A., et al. (2009). "I don't make the soups anymore": Pre- to post-migration dietary and lifestyle changes among Latinos living in west-central Florida. Ecology of Food and Nutrition, 46(5-6), 427-444.

51. Patil, C., Hadley, C., \& Nahayo, P. (2009). Unpacking dietary acculturation among new Americans: Results from formative research with African refugees. Journal of Immigrant and Minority Health, 11(5), 342-358.

52. Lowe, M. (2010). Contemporary rural-urban migration in Alaska. Alaska Journal of Anthropology, 8(2), 75-90.

53. Coble, J. D., \& Rhodes, R. E. (2006). Physical activity and native Americans: A review. American Journal of Preventive Medicine, 31(1), 36-46.

54. Cunningham-Sabo, L., et al. (2008). Qualitative investigation of factors contributing to effective nutrition education for Navajo families. Maternal and Child Health Journal, 12(Suppl 1), 68-75.
55. Jernigan, V. B. B. (2010). Community-based participatory research with Native American communities: The chronic disease self-management program. Health Promotion Practice, 11(6), 888-899.

56. Selle, M. (2007). Traditional food access for Alaska native elders in anchorage long term care facilities: UMI dissertation services. Ann Arbor, MI: ProQuest Information and Learning.

57. Sharma, S., et al. (2010). Addressing the public health burden caused by the nutrition transition through the healthy foods north nutrition and lifestyle intervention programme. Journal of Human Nutrition \& Dietetics, 23, 120-127.

58. Dogra, S., \& Stathokostas, L. (2012). Sedentary behavior and physical activity are independent predictors of successful aging in middle-aged and older adults. Aging Research, 2012, 1-8.

59. Marques, E. A., et al. (2014). Risk for losing physical independence in older adults: The role of sedentary time, light, and moderate to vigorous physical activity. Maturitas, 79, 91-95.

60. Swartz, A., et al. (2007). Ambulatory activity and body mass index in White and non-White older adults. Journal of Physical Activity and Health, 4(3), 294-304.

61. Hopping, B. N., et al. (2010). High levels of physical activity and obesity co-exist amongst inuit adults in Arctic Canada. Journal of Human Nutrition \& Dietetics, 23, 110-114.

62. Redwood, D. G., et al. (2009). Physical activity patterns of American Indian and Alaskan native people living in Alaska and the southwestern United States. American Journal of Health Promotion, 23(6), 388-395.

63. Slattery, M. L., et al. (2010). Associations among body mass index, waist circumference, and health indicators in American Indian and Alaska native adults. American Journal of Health Promotion, 24(4), 246-254.

64. Bachar, J. J., et al. (2006). Cherokee choices: A diabetes prevention program for American Indians. Preventing Chronic Disease, 3(3), A103.

65. Brown, B. D., et al. (2010). Translating the diabetes prevention program for northern plains Indian youth through communitybased participatory research methods. Diabetes Education, 36(6), 924-935.

66. Gennuso, K. P., et al. (2013). Sedentary behavior, physical activity, and markers of health in older adults. Medicine and Science in Sports and Exercise, 45(8), 1493-1500.

67. Matthews, C. E., et al. (2008). Amount of time spent in sedentary behaviors in the United States, 2003-2004. American Journal of Epidemiology, 167(7), 875-881.

68. Tennant, B., Stellefson, M., Dodd, V., Chaney, B., Chaney, D., Paige, S., et al. (2015). eHealth Literacy and Web 2.0 health information seeking behaviors among baby boomers and older adults. Journal of Medical Internet Research, 17(3), e70.

69. Choi, L. H. (2003). Factors affecting volunteerism among older adults. Journal of Applied Gerontology, 22(2), 179-196.

70. Reger, B., et al. (2002). Wheeling walks: A community campaign using paid media to encourage walking among sedentary older adults. Preventive Medicine, 35(3), 285-292.

71. Chui, H., et al. (2014). Social partners and momentary affect in the oldest-old: The presence of others benefits affect depending on who we are and who we are with. Developmental Psychology, 50(3), 728

72. Beverly, E. A., Miller, C. K., \& Wray, L. A. (2008). Spousal support and food-related behavior change in middle-aged and older adults living with type 2 diabetes. Health Education \& Behavior, 35(5), 707-720.

73. Gao, X., Nelson, M. E., \& Tucker, K. L. (2007). Television viewing is associated with prevalence of metabolic syndrome in Hispanic elders. Diabetes Care, 30(3), 694-700.

74. Haber, D. (2013). Health promotion and aging: Practical applications for health professionals. New York: Springer. 
75. Schoenberg, N., et al. (2014). Addressing health inequities in Appalachian Kentucky through community-engaged interventions: Reflections after 10 years of applied research. Practicing Anthropology, 36(4), 31-36.

76. Swanson, M., et al. (2011). Intergenerational energy balance interventions: A systematic literature review. Health Education Behavior, 38(2), 171-197.
Publisher's Note Springer Nature remains neutral with regard to jurisdictional claims in published maps and institutional affiliations. 